\title{
Influence of the Soil-Structure Interaction in the Behavior of Mat Foundation
}

\author{
Oustasse Abdoulaye Sall1*, Meissa Fall'1, Yves Berthaud², Makhaly Ba1, Mapathé Ndiaye1 \\ ${ }^{1}$ Département of Génie Civil, UFR SI-Université de Thiès, Thiès, Sénégal \\ ${ }^{2}$ Université Pierre et Marie Curie, Paris, France \\ Email: oustaz.sall@univ-thies.sn
}

Received 29 January 2014; revised 28 February 2014; accepted 7 March 2014

Copyright (C) 2014 by authors and Scientific Research Publishing Inc.

This work is licensed under the Creative Commons Attribution International License (CC BY).

http://creativecommons.org/licenses/by/4.0/

(c) (i) Open Access

\begin{abstract}
This article focuses on the study of the behavior of a soil mass under a plate subjected to a uniformly distributed load. The aim of this paper is to highlight the soil-structure interaction with a linear variation of the mechanical properties of the soil with the depth. The theory of plates and the soil-structure interaction has allowed reaching the general equation of the problem which depends on both the mechanical properties of the concrete and the subgrade. This study shows that the linearity of the elastic modulus of subgrade leads to larger displacements when this modulus is assumed to be constant in the soil mass. It also shows that the Poisson's ratio of soil and mechanical properties of the concrete have an insignificant influence on the displacements. This analysis also shows that the points in the upper half-thickness of soil are the most sensitive to the parameters of the model.
\end{abstract}

\section{Keywords}

Mat Foundation; Plate Theory; Soil-Structure Interaction; Mechanical Properties

\section{Introduction}

To calculate the displacement in a foundation most of civil engineering structure computing software admits a constant elastic modulus. The calculation of displacements in a foundation requires to model realistically the behavior of the soil foundation. This requires the definition of models of behavior adapted to foundation soils. To approach the reality, a linear elastic constitutive law, perfectly plastic (such as Mohr Coulomb law) can be introduced (Coquillay, 2005) [1] for varying linearly the parameters $(E, v, c \cdots)$ with the depth. It is generally agreed that the Young's modulus of homogeneous soil increases with depth. This can be explained by an in-

\footnotetext{
"Corresponding author.
} 
crease in the mean stress and the densification it leads. In this context the variation of the soil elastic modulus $\left(E_{s}\right)$ can be given by the following expression:

$$
E_{s}=E_{1}(1-z / H)+\frac{z}{H} E_{2}
$$

where $E_{1}$ and $E_{2}$ are the elastic modulus respectively at the top and the bottom of the soil mass.

In what follows, the profile of displacements in the soil mass is studied. To do this it is assumed at first that $\phi(z)$ and the elastic modulus $\left(E_{s}\right)$ of the soil foundation are linear, and the Poisson ratio of the soil $\left(v_{s}\right)$ is constant with the depth of the foundation massif. Secondly, the linearity of Poisson's ratio and an hyperbolic sine variation of the function $\phi(z)$ are introduced.

\section{Modelisation}

Using the model of the elastic continuum, Vlazov (1949) [2] proposed a formulation for modeling soil, based on the application of the variational method. The soil layer of thickness $\boldsymbol{H}$ is considered as a linear isotropic elastic medium, resting on a rigid substrate (Figure 1) [3]. The horizontal displacements $u(x, y, z)$ and $v(x, y, z)$ are assumed to be zero in the whole mass of soil. The vertical displacements are given by:

$$
w(x, y, z)=w(x, y) \phi(z)
$$

where $\phi(z)$ is a function which describes the variation of the displacements $w(x, y)$ along the $z$ axis, such that: $\phi(0)=1$ and $\phi(H)=0$.

$\phi(z)$ can be expressed by the following relationships:

$$
\begin{gathered}
\phi(z)=(1-z / H) \\
\phi(Z)=\frac{\sinh \left[(H-z) \frac{\gamma}{L}\right]}{\sinh \left(\frac{\gamma H}{L}\right)}
\end{gathered}
$$

$\gamma$ and $L$ are constants parameters.

The equilibrium equations in the $z$ direction are obtained by applying the principle of virtual work (Turhan, 1992) [4]. Thus the total response of the system under a load $(q)$, taking into account the soil-structure interaction, is given by:

$$
D\left(\frac{\partial^{4} w}{\partial x^{4}}+2 \frac{\partial^{4} w}{\partial x^{2} \partial y^{2}}+\frac{\partial^{4} w}{\partial y^{4}}\right)-2 T\left(\frac{\partial^{2} w}{\partial x^{2}}+\frac{\partial^{2} w}{\partial y^{2}}\right)+k w=q(x, y)
$$

where $D$ is the flexural rigidity of the plate and is given by:

$$
D=\frac{E_{b} e^{3}}{12\left(1-v_{b}^{2}\right)}
$$

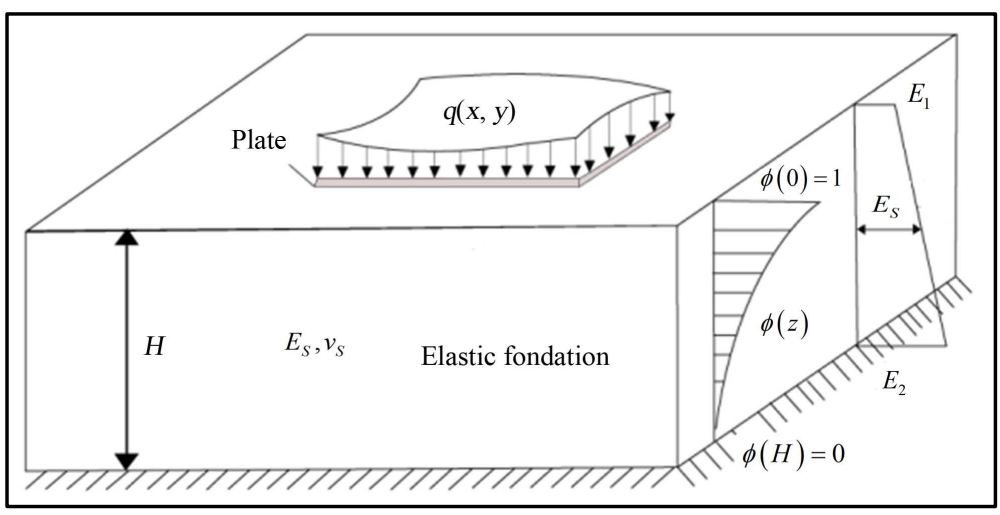

Figure 1. Vlasov model, stresses in an elastic layer (Selvadurai, 79). 
with:

$\boldsymbol{E}_{\boldsymbol{b}}$ : elastic modulus of the plate,

$\boldsymbol{e}$ : the thickness of the plate,

$v_{b}$ : the Poisson's ratio of the plate.

$\mathbf{2 T}$ and $\boldsymbol{k}$ are the two parameters of the Vlasov model;

$\boldsymbol{k}$ is the modulus of subgrade reaction expressed by Biot (1935) [5] according to the following relationship:

$$
k=\frac{0.65 E_{s}}{1-v_{s}^{2}} \times \sqrt[12]{\frac{E_{s} B^{4}}{E_{b} I}}
$$

Vesic (1963) [6] improved the formula of Biot and proposed the following relationship:

$$
k=\frac{0.95 E_{s}}{1-v_{s}^{2}}\left(\frac{E_{s} B^{4}}{\left(1-v_{s}^{2}\right) E_{b} I}\right)^{0.108}
$$

where:

$\boldsymbol{E}_{s}$ is the modulus of subgrade;

$\boldsymbol{v}_{\boldsymbol{s}}$ is the Poisson's ratio of subgrade;

$\boldsymbol{B}$ is the width of the foundation;

$\boldsymbol{E}_{\boldsymbol{b}}$ is the Young's modulus of the concrete;

$\boldsymbol{I}$ is the moment of inertia of the cross section of the concrete.

$\boldsymbol{T}$ is the horizontal elastic modulus of subgrade reaction proposed by Vlasov (1949) as follows:

$$
T=\frac{E_{s}}{4\left(1-v_{s}^{2}\right)\left(1+v_{s}\left(1-v_{s}\right)\right)} \int_{0}^{H} \phi^{2} d z
$$

For a relatively deep layer of soil where the normal stresses may vary with depth, it is possible to use, for the function $\phi(z)$, the non-linear continuously variation defined by Equation (4).

Indeed, the profile of hyperbolic sine requires an estimation of the arbitrary parameter $\gamma$ which Vlazov (1949)

[2] did not specify the value. This author just recommended values between 1 and 2.

\section{Analytical Solution}

For the case of an elastic homogeneous soil, it can be assumed a uniform distribution of the applied force on the foundation system. This amount to an admission that the stress $q(x, y)$ is a constant $Q$ value in every point of the structure. For a foundation of infinite dimension, zero displacement at the edges of the plate is imposed. Using the double Fourier series and accounting for the displacement of the soil under the effect of the own weight of the slab, the displacement at any point of the system is given by:

$$
w(x, y, z)=\frac{16 Q}{\pi^{2}}\left(\sum_{1,3,51,3,5}^{\infty} \sum_{\operatorname{Dmn}\left(\left(\frac{m \pi}{L}\right)^{2}+\left(\frac{n \pi}{B}\right)^{2}\right)^{2}+2 T m n\left(\left(\frac{m \pi}{L}\right)^{2}+\left(\frac{n \pi}{B}\right)^{2}\right)+k m n}^{\sin \left(\frac{m \pi x}{L}\right) \times \sin \left(\frac{n \pi y}{B}\right)}+25000 \times \frac{e}{k}\right) \times \phi(z)
$$

The maximum values of $\boldsymbol{m}$ and $\boldsymbol{n}$ are set to 45 as above 25 the sensibility relative to $\mathrm{m}$ and $\mathrm{n}$ is no longer perceptible.

It appears from the study of Sall et al. (2013) [7] that the elastic modulus and the Poisson's ratio of the subgrade are the most influential parameters on the displacements of the plate. The modulus of subgrade reaction and displacements vary slightly with the mechanical properties of concrete and are more influenced by the elastic modulus of the soil.

\section{Numerical Validation of Results}

In order to validate the results, a concrete slab resting on an elastic soil with constant Young's modulus is con- 
sidered.

With $B=20 \mathrm{~m}, L=20 \mathrm{~m}, e=0.4 \mathrm{~m} ; E_{b}=33 \mathrm{GPa}, E_{s}=7 \mathrm{MPa}, v_{s}=0.2$ and $Q=15 \mathrm{t} / \mathrm{m}^{2}$.

The values of the vertical according to Biot and horizontal elastic modulus are calculated and fed into a finite element software ("Flexion des plaques" under "RDM 6" module) leads to the results. After analyzing the results from "Flexion des plaques" the Castem ${ }^{\odot}$ finite element code is used to understand the influence of parameters on the results. $\boldsymbol{k}$ values given by Biot were used because they are lower than those given by Vesic. The more $\boldsymbol{k}$ is significant, the more displacements are low. However, to avoid underestimating displacements, $k$ values given by Biot are used in this research.

\subsection{Analysis of Displacements Provided by "Flexion Des Plaques"}

The mesh is given by the Figure 2 .

For boundary conditions, it is assumed a displacement equal to the displacement of the interface under the effect of the weight of the slab.

The results are given in Figure 3 which shows that the displacement is most important at the center of the plate.

The following figure visualizes the shape of the displacement along the median of the plate. From Figure 4, it can be said that there is a correlation between the displacements given by the analytical model and those of the finite element method ("Flexion des plaques").

Note that the maximum displacement obtained in the numerical calculation is $5 \mathrm{~mm}$ higher than the maximum value of the analytical calculation. This difference in displacement values can be explained by the fact that during the numerical simulation, the elastic supports match the nodes corresponding to the mesh.

But in reality, the elastic support is extended under all the plate which contributes to reduce the displacements.

For the same given parameters, the influence of Poisson's ratio of concrete on the displacements is evaluated. Table 1 gives a summary of this influence on the maximum displacement $\left(w_{\max }\right)$.

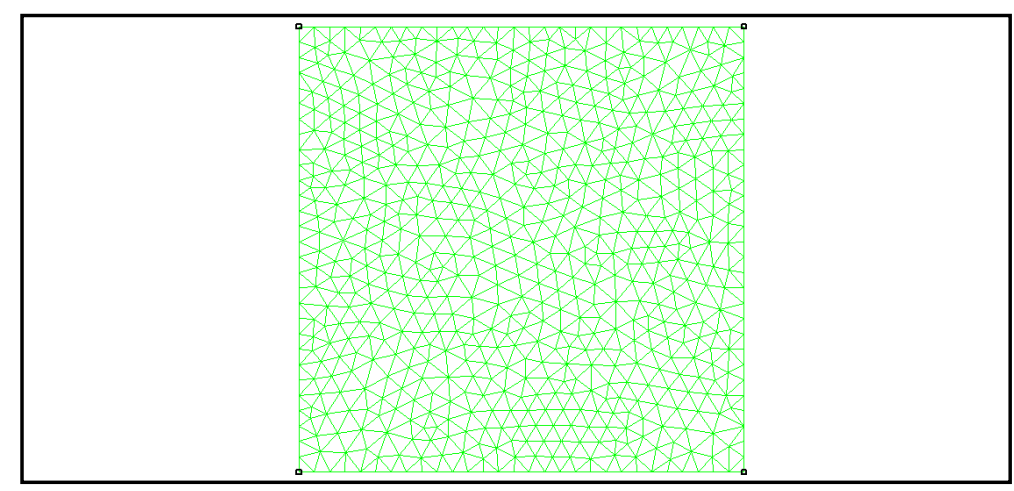

Figure 2. Mesh of the plate by finite elements.

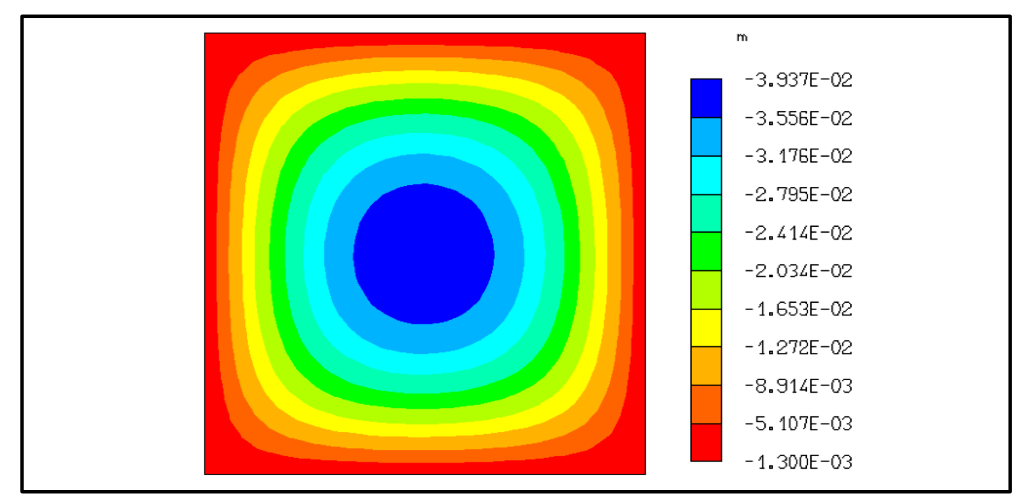

Figure 3. Displacements cartography. 
Table 1. $w_{\max }$ according to $v_{b}$.

\begin{tabular}{cccccc}
\hline$\left(v_{b}\right)$ & 0.2 & 0.25 & 0.3 & 0.4 & 0.45 \\
$w_{\max }(\mathrm{cm})$ & 3.753 & 3.752 & 3.75 & 3.744 & 3.74 \\
\hline
\end{tabular}

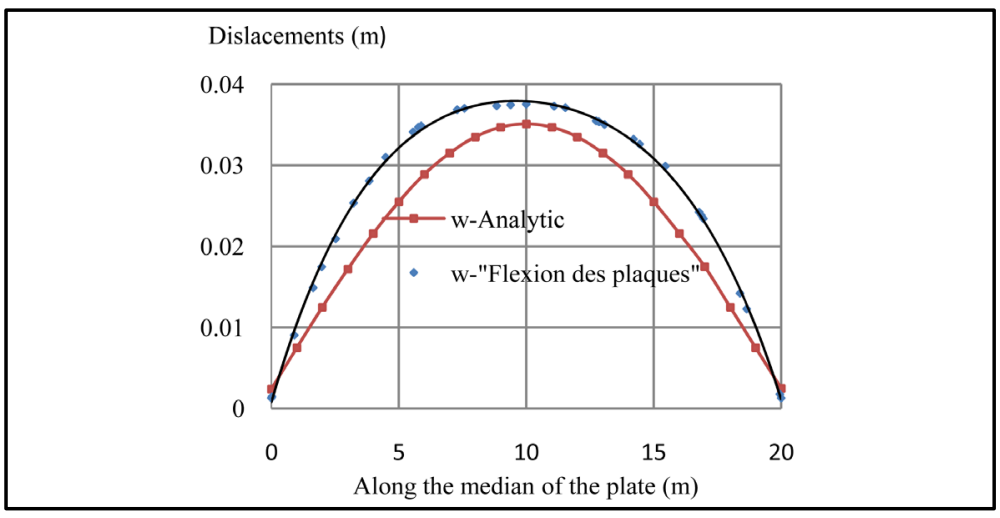

Figure 4. Displacements along the median of the plate.

Table 1 shows a weak influence of Poisson's ratio on the displacements of the soil-structure interface. These displacements vary in the range of one to four hundredths of a millimeter when the Poisson's ratio ranges from 0.25 to 0.45 . Then, the displacements are quasi independent of Poisson's ratio of the concrete.

In the following, it is proposed to study the influence of the elastic modulus of the concrete foundation displacements of the structure as shown in Table 2 . To do so, a concrete slab of the same dimensions $(20 \mathrm{~m} \times 20 \mathrm{~m}$ $\times 40 \mathrm{~cm}$ ) with a Young's modulus ranging between 33 and $46 \mathrm{GPa}$, is subjected to an uniform loading $\left(15 \mathrm{t} / \mathrm{m}^{2}\right)$. The slab rests on an elastic soil of constant Young's modulus equal to $7 \mathrm{MPa}$ and Poisson's ratio equal 0.2. The different values of $\boldsymbol{w}_{\max }$ for various values of the elastic modulus of the concrete are shown in Table 2 . The Figures 5-7 show the displacements cartography for various values of $\boldsymbol{E}_{\boldsymbol{b}}$.

Table 2 gives a summary of the maximum value for different Young's modulus of concrete.

The above analysis shows that the Young's modulus of the concrete has an insignificant influence on the displacement of the plate resting on elastic foundation.

To study the influence of the elastic modulus of the subgrade on the displacements of the plate, the previous data are considered, the Young's modulus of concrete is set as at a constant value and the modulus of the soil is varying from 4 to $8 \mathrm{MPa}$.

It appears from this study that the elastic modulus of subgrade has a considerable influence on the displacements of the plate (Figures 8-10).

\subsection{Analysis of Displacements Provided by Castem $^{\odot}$}

In order to confirm the validity of the results, another finite element code $\left(\right.$ Castem $\left.^{\odot}\right)$ is used to study the influence of different model parameters. The results provided by Castem ${ }^{\odot}$ will be compared with results provided by the analytical model and reported in the Figure 11.

The influence of other parameters provided by Castem $^{\circledR}$ is given in Tables 3-6:

It is clear from this analysis that the parameters of the subgrade $\left(E s, v_{s}\right)$ have a greatest influence on the displacements of the plate. The properties of the concrete $\left(E_{b}, v_{b}\right)$ have a weak influence on the displacements. This which just comfort the analysis of analytical results given by Sall et al. [7].

In what follows, the influence of mechanical properties of soil and concrete foundation on displacements of soil mass is studied.

Figures 12-17 show the influence of model parameters on displacements of the soil foundation. These results show that soil parameters are more influential than those of the concrete foundation. It should be noted that the concrete properties, especially the Poisson's ratio, have not substantially influenced the displacements profile (Figure 16).

These results show that the elastic modulus of the substrate has an influence more or less significant on the 
Table 2. $w_{\max }$ values according to $v_{b}$.

\begin{tabular}{cccc}
\hline$v_{\boldsymbol{b}}(\mathrm{GPa})$ & 43 & 36 & 33 \\
$w_{\max }\left(10^{-2} \mathrm{~m}\right)$ & 2.99 & 3.02 & 3.082 \\
\hline
\end{tabular}

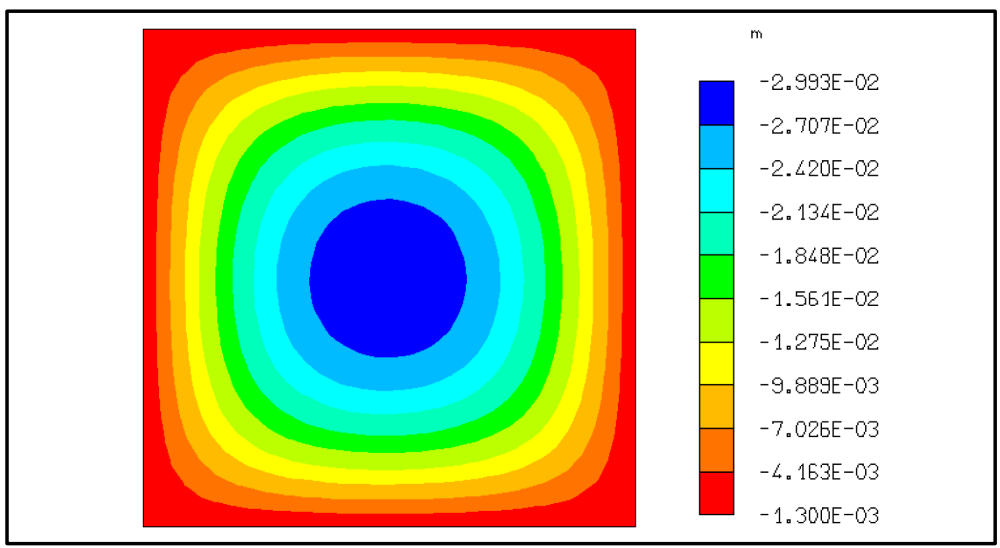

Figure 5. Displacements cartography for $E_{b}=46 \mathrm{GPa}$.

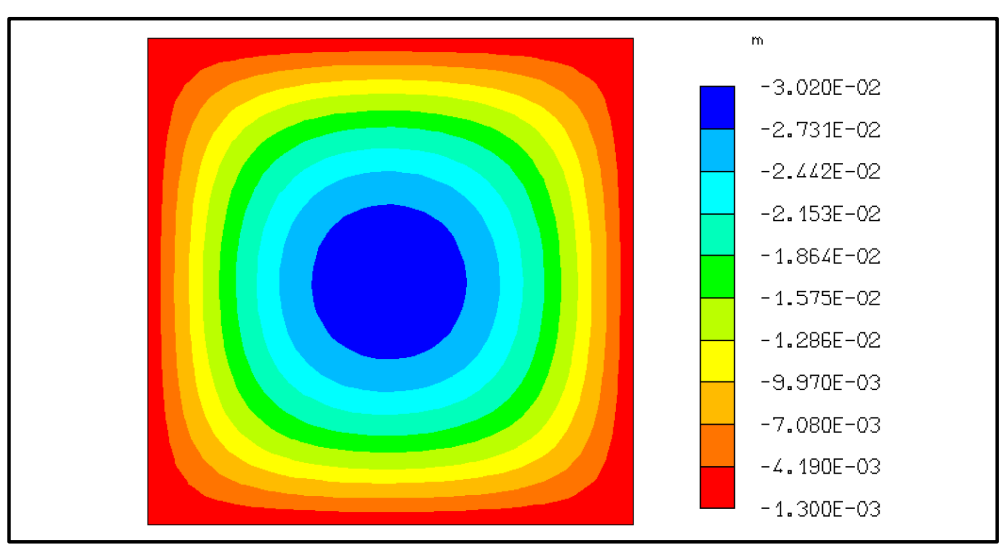

Figure 6. Displacements cartography for $E_{b}=36 \mathrm{GPa}$.

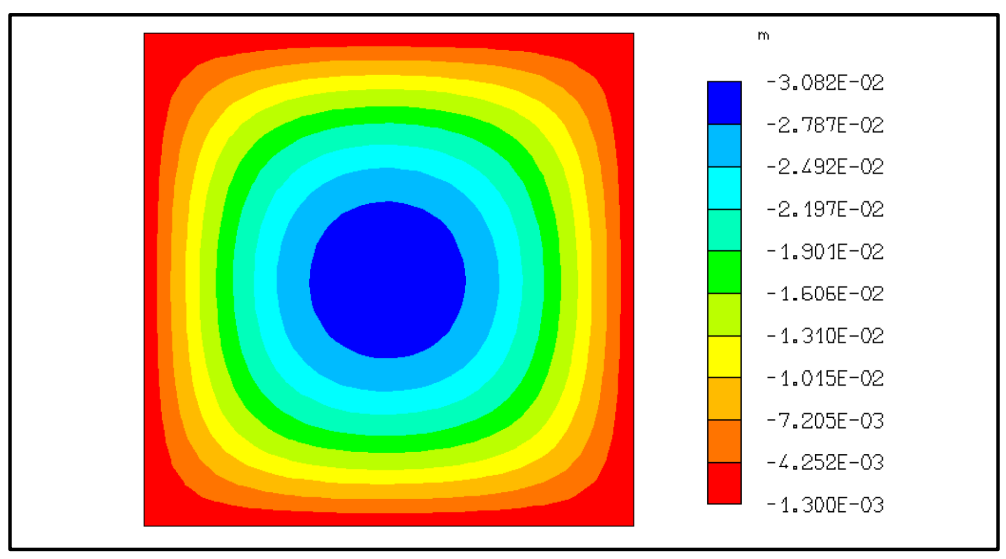

Figure 7. Displacements cartography for $E_{b}=33 \mathrm{GPa}$.

displacements of points located above the middle of the soil mass and a less pronounced effect on the displacements of points near the bedrock and the top of the soil mass (Figure 13). 


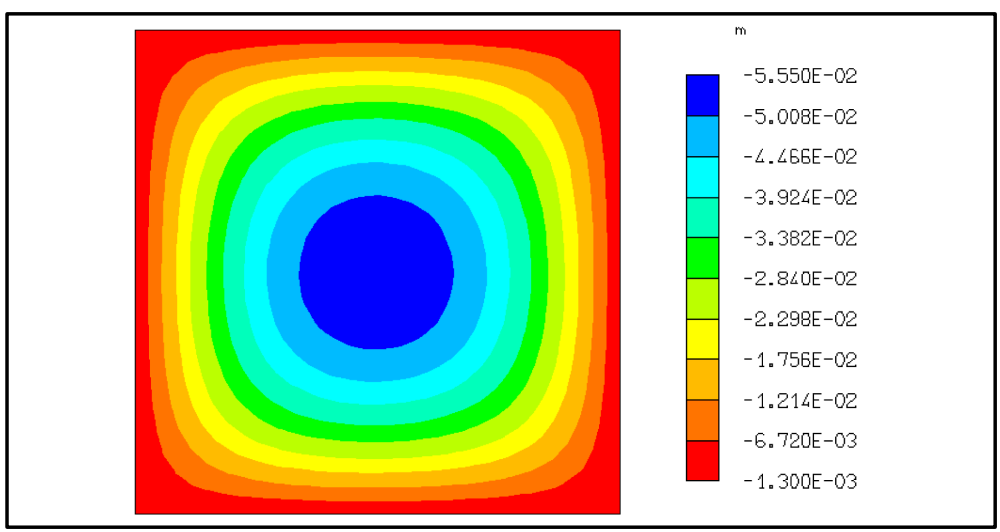

Figure 8. Displacements cartography for $E_{s}=4 \mathrm{MPa}$.

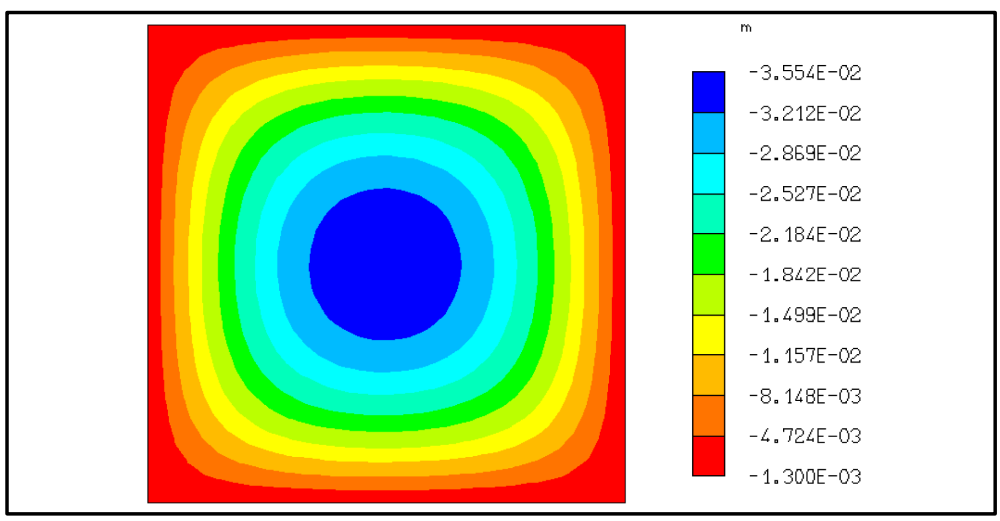

Figure 9. Displacements cartography for $E_{s}=6 \mathrm{MPa}$.

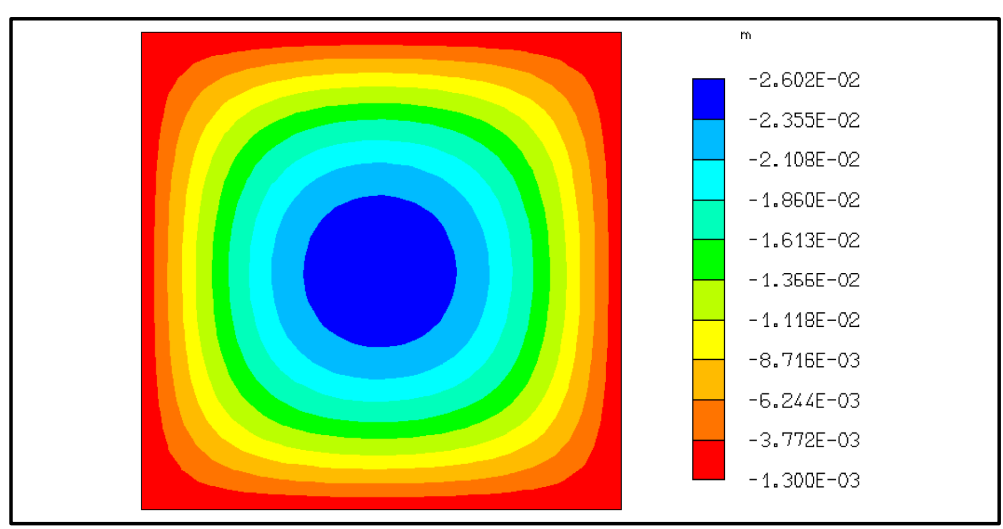

Figure 10. Displacements cartography for $E_{s}=8 \mathrm{MPa}$.

Table 3. $w_{\max }$ values according Castem $^{\circledR}$ according to $E_{b}$.

\begin{tabular}{ccccc}
\hline$E_{b}(\mathrm{GPa})$ & 33 & 36 & 39 & 43 \\
$w_{\max }(\mathrm{cm})$ & 4.01793 & 4.01792 & 4.01791 & 4.01790 \\
\hline Table 4. $w_{\max }$ values according Castem ${ }^{\odot}$ according to $v_{s}$. & & & \\
\hline$v_{s}$ & 0.2 & 0.25 & 0.35 & 0.4 \\
$w_{\max .}(\mathrm{cm})$ & 4.01793 & 3.72031 & 2.78166 & 2.0834 \\
\hline
\end{tabular}


Table 5. $w_{\max }$ values according Castem $^{\odot}$ according to $v_{b}$.

\begin{tabular}{ccccc}
\hline$v_{b}$ & 0.2 & 0.25 & 0.35 & 0.4 \\
$w_{\text {max. }}(\mathrm{cm})$ & 4.01793 & 4.01792 & 4.01790 & 4.01789 \\
\hline Table 6. $w_{\max }$ values according Castem $^{\odot}$ & according to $e$. & & & 80 \\
\hline$e(\mathrm{~cm})$ & 20 & 40 & 60 & 4.01799 \\
\hline$w_{\text {max. }}(\mathrm{cm})$ & 4.01789 & 4.01793 & 4.01796 & \\
\hline
\end{tabular}

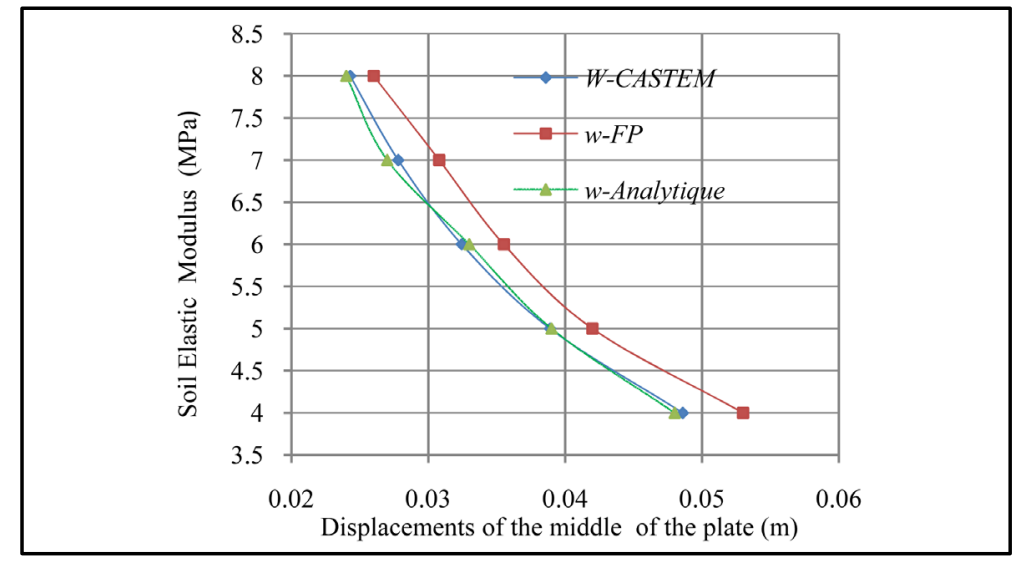

Figure 11. Displacements of the middle of the plate according to $E_{s}$.

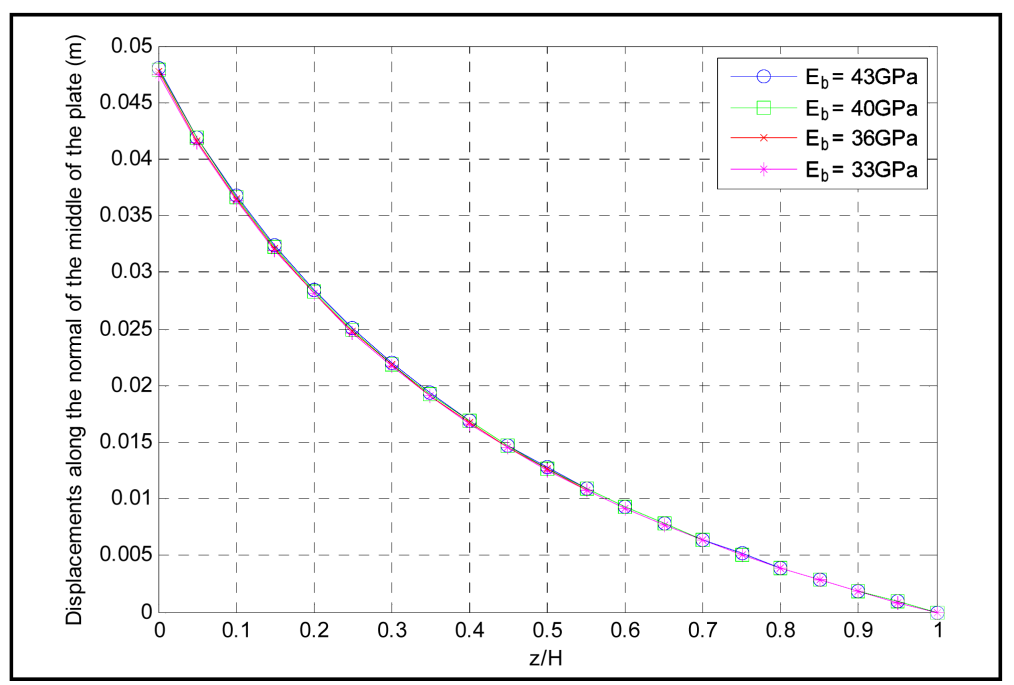

Figure 12. Profile of the displacements from the interface to the rigid substratum for various values of $E_{b}$.

These results show also a discernible influence of the elastic modulus of the top of the soil. The influence of Young's modulus of top of the soil is more pronounced on the half-height above the soil. The upper half-height is the most affected part of the soil. Figure 18 shows the influence of the ratio B/L on the profile of displacements in the soil.

In which follows in addition to the linearity of the soil elastic modulus, the linearity of Poisson's ratio is introduced. It is assumed that variation of $\phi(z)$ follows a hyperbolic sine. The Poisson's ratio in this context is given by: 


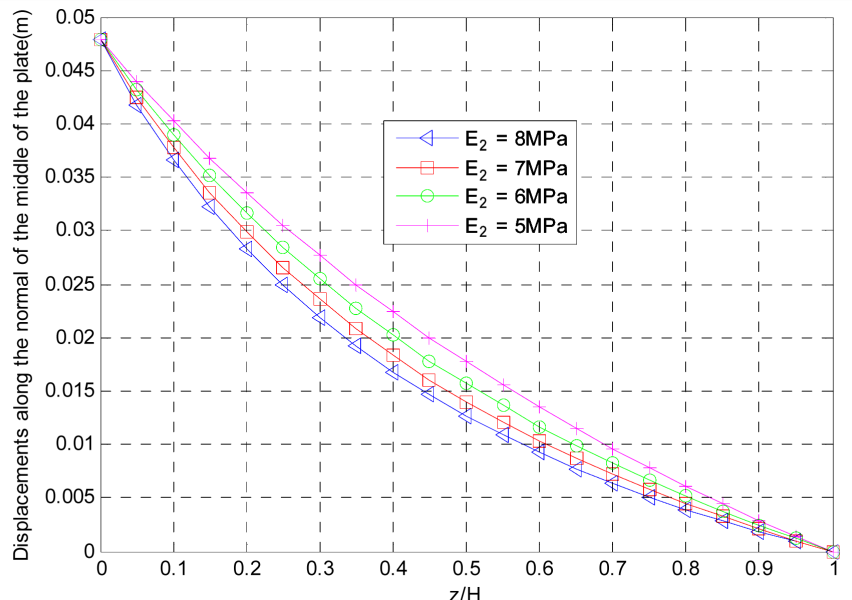

Figure 13. Profile of the displacements from the interface to the rigid substratum for various values of $E_{2}$.

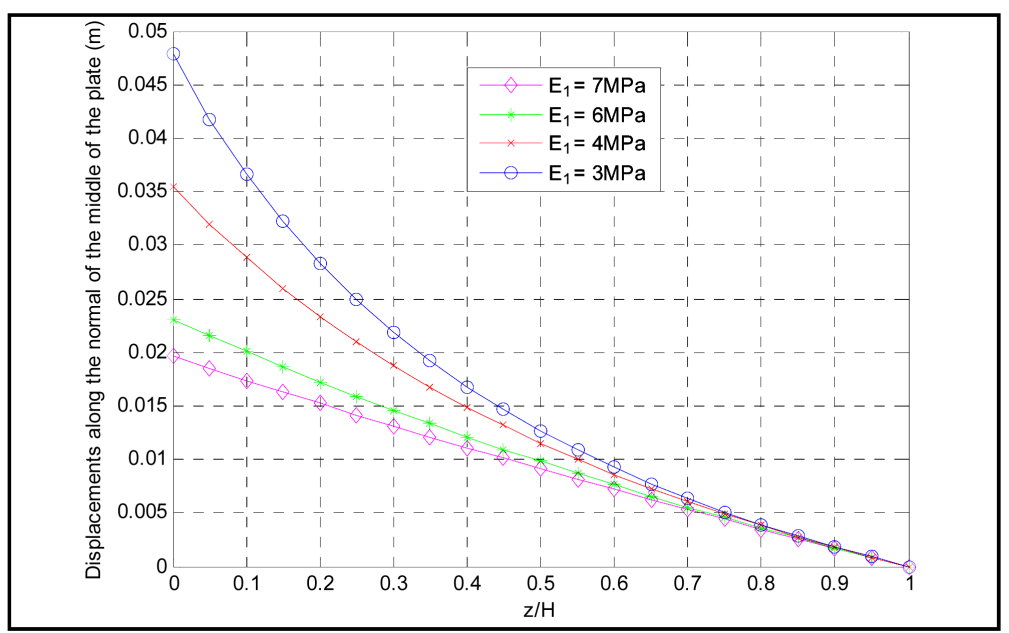

Figure 14. Profile of the displacements from the interface to the rigid substratum for various values of $E_{1}$.

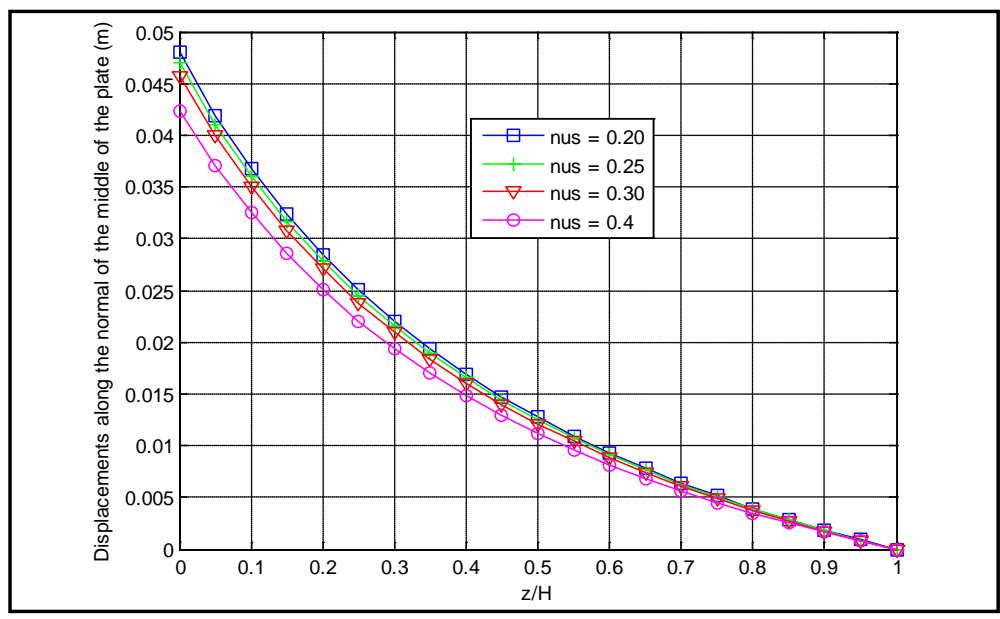

Figure 15. Profile of the displacements from the interface to the rigid substratum for various values of $v_{s}$. 


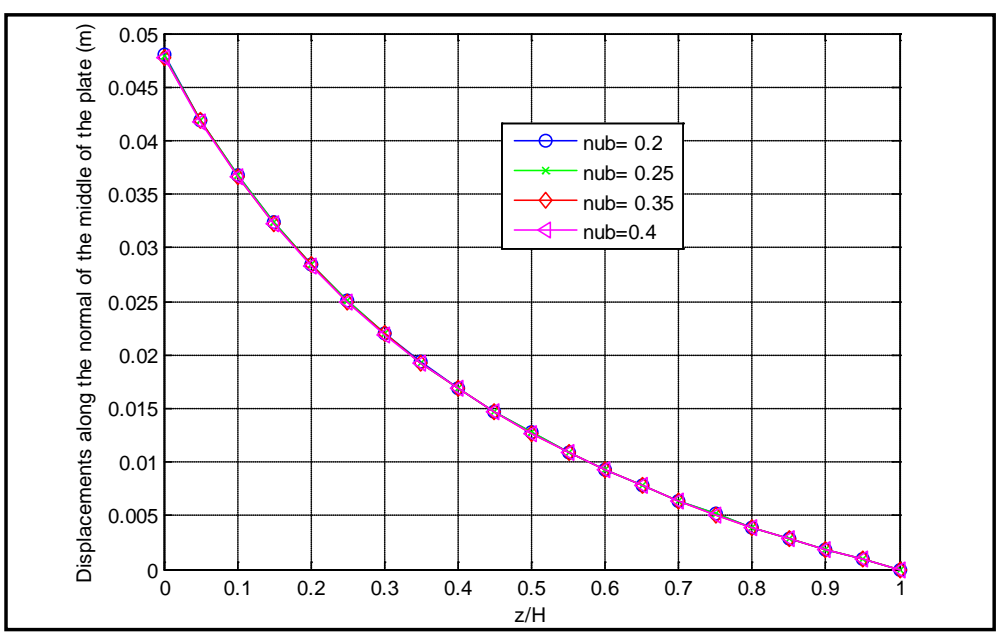

Figure 16. Profile of the displacements from the interface to the rigid substratum for various values of $v_{b}$.

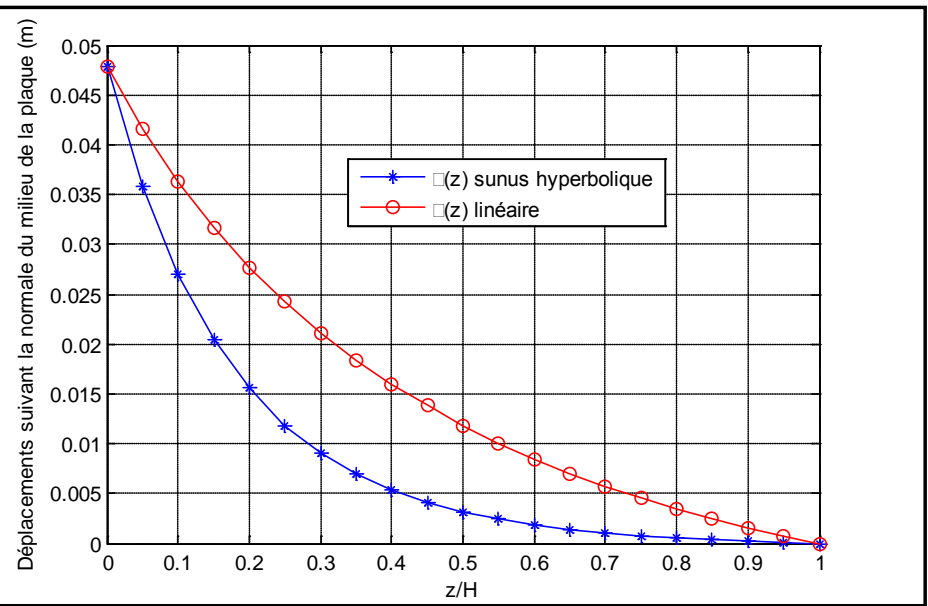

Figure 17. Profile of the displacements from the interface to the rigid substratum for various expression of $\phi(z)$.

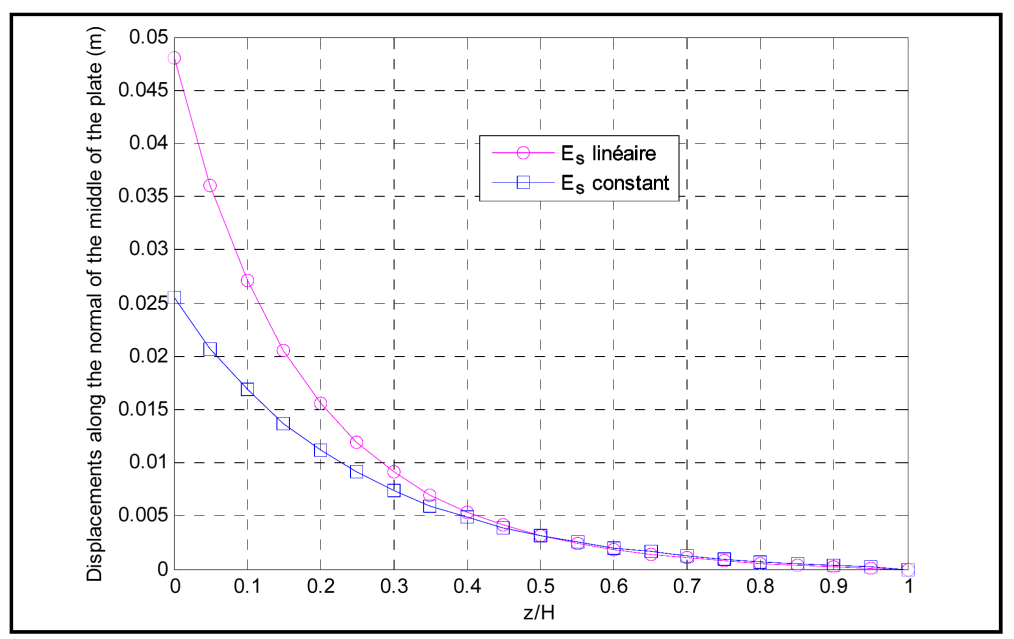

Figure 18. Profile of the displacements from the interface to the rigid substratum for linear and constant $E_{s}$. 


$$
v_{s}=v_{1}(1-z / H)+\frac{z}{H} v_{2}
$$

with $\boldsymbol{v}_{\mathbf{1}}$ and $\boldsymbol{v}_{\mathbf{2}}$ respectively representing the Poisson's ratios of the top and the bottom of the soil.

Figures 17-24 show the influence of the parameters of a linear model with the elastic modulus and Poisson's ratio. It is clear from this analysis that the settlements in the soil mass are more pronounced for $\phi(z)$ hyperbolic sine for a linear profile (Figure 17).

Figure 17 shows the importance of controlling the stress path and strain in the soil foundation. The linearity of the elastic modulus of soil gives more pronounced displacements in the soil (especially on the upper half thick of the soil) than when a constant elastic modulus of subgrade is admitted.

These results also show a small influence of the linearity of Poisson's ratio on the displacements profile (Figure 22).

Figure 23 shows the influence of the thickness on the profile of the settlements in the soil. The influence of the thickness of the plate is more observed on the upper half thickness of the soil.

This figure confirms that the thicker is the plate the more important are settlements in the soil massif.

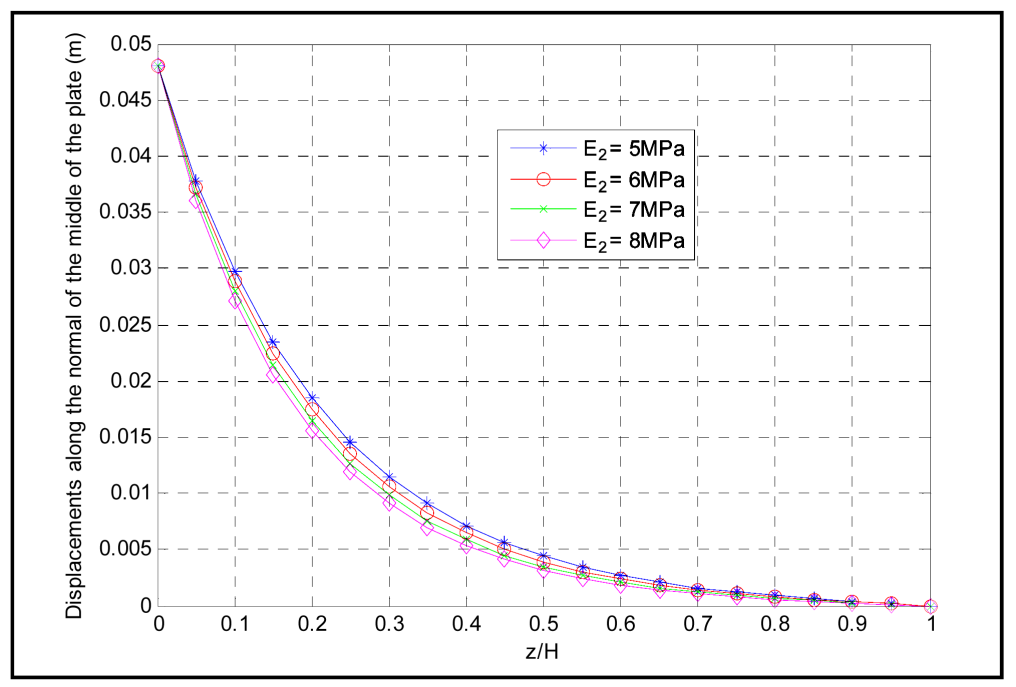

Figure 19. Profile of the displacements from the interface to the rigid substratum for various values of $E_{2}$.

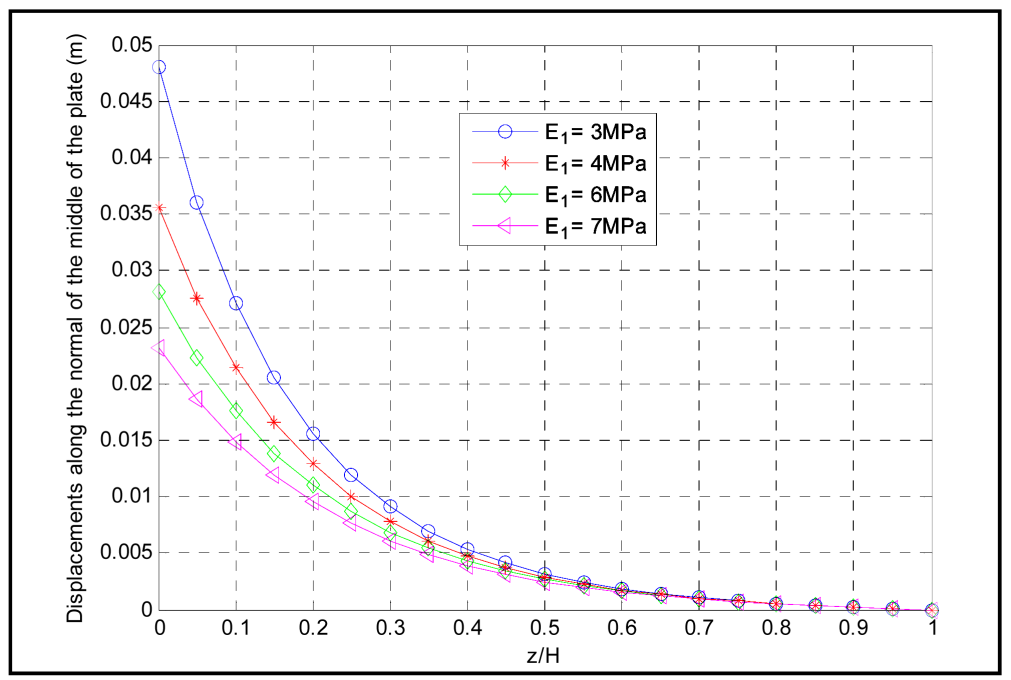

Figure 20. Profile of the displacements from the interface to the rigid substratum for various values of $E_{1}$. 


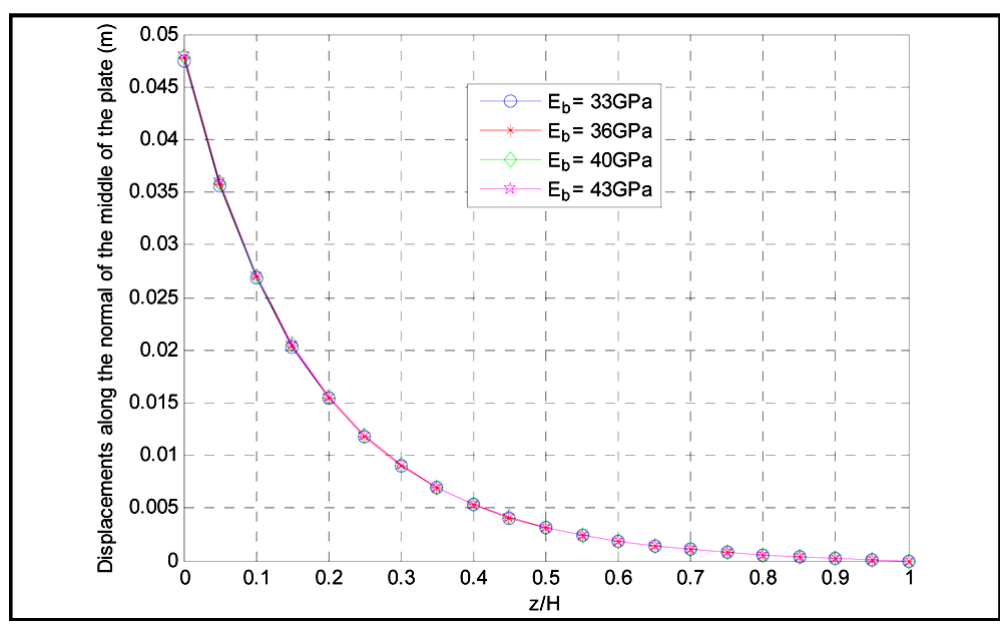

Figure 21. Profile of the displacements from the interface to the rigid substratum for various values of $E_{b}$.

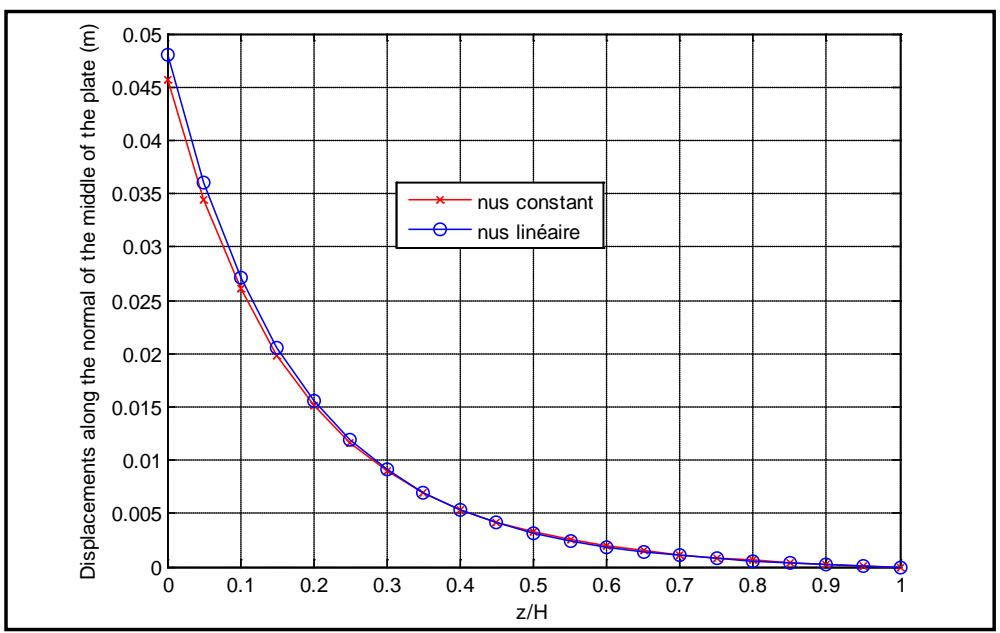

Figure 22. Profile of the displacements from the interface to the rigid substratum for linear and constant $v_{s}$.

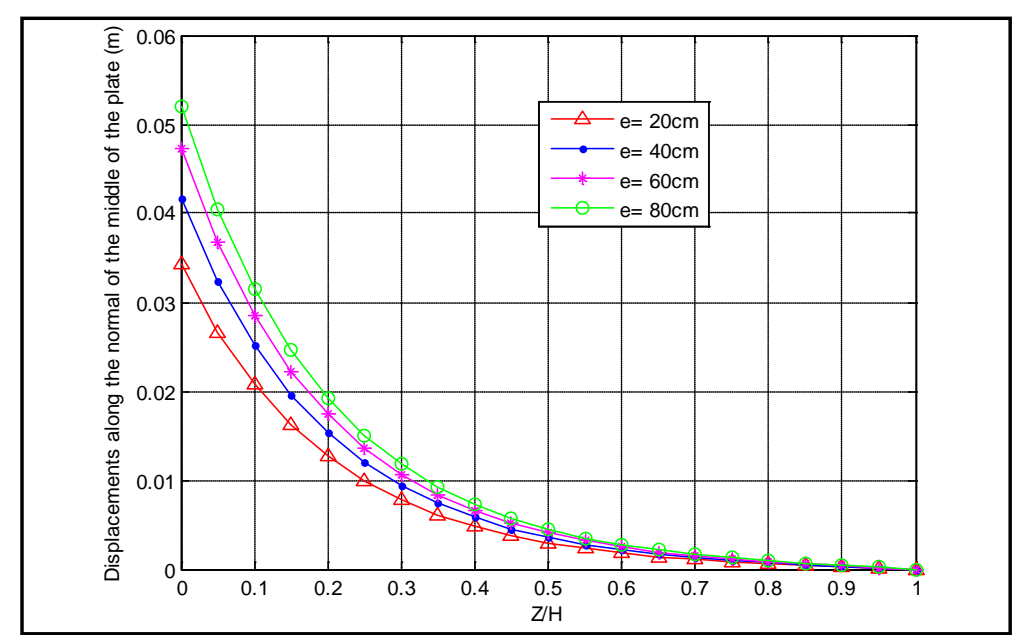

Figure 23. Profile of the displacements from the interface to the rigid substratum for various values of $e$. 


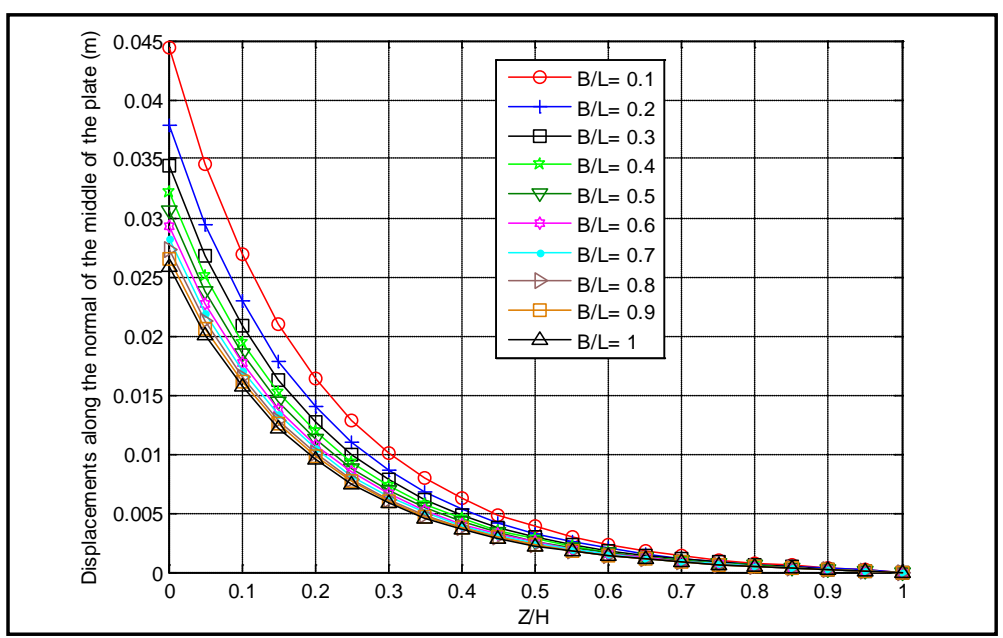

Figure 24. Profile of the displacements from the interface to the rigid substratum for various values of $B / L$.

It is clear from these findings that the influence of model parameters on the profile of displacements is more pronounced on the upper half-thickness of the soil.

Figure 18 shows the displacements for constant and linear soil modulus. It is clear from this figure that taking a constant modulus leads to underestimate displacements because linearity of $E_{s}$ gives greater displacements at points on the upper half-thickness of the soil.

\section{Conclusion}

It appears from this study that the linearity of the elastic modulus of subgrade leads to greater displacement than when this modulus is assumed to be constant in the soil. The points located in the upper half-thickness of soil are the most sensitive to the parameters of the model. Poisson's ratio has an insignificant influence on the observed displacements. This study shows that the mastery of mechanical properties and the path of displacements in the soil is important for mastering the future life of the structure where the need to pay utmost importance on soil studies before calculation and construction of any foundation. This study shows that the concrete alone does not solve all problems related to disorders in a foundation and mastery of soil parameters is important to minimize disorders.

\section{References}

[1] Coquillay, S. (2005) Prise en Compte de la non Linéarité du Comportement des sols Soumis à de Petites Déformations pour le Calcul des Ouvrages Géotechniques. Thèse de Doctorat de l’Ecole Nationale des Ponts et Chaussées, Paris.

[2] Vlazov, V.Z. and Leontiev, U.N. (1966) Beams, Plates and Shells on Elastic Foundations. Israel Program for Scientific Translations, Jerusalem.

[3] Selvadurai, A.P.S. (1979) Elastic Analysis of Soil-Foundation Interaction. Developments in Geotechnical Engineering, 17, Elsevier Scientific Publishing Company, New York.

[4] Turhan, A. (1992) A Consistent Vlasov Model for Analysis on Plates on Elastic Foundation Using the Finite Element Method. The Graduate Faculty of Texas Tech University in Partial Fulfillment of the Requirements for the Degree of Doctor.

[5] Biot, M.A. (1937) Bending of an Infinite Beam on an Elastic Foundation. Journal of Applied Physics, 12, 155-164. http://dx.doi.org/10.1063/1.1712886

[6] Vesic, A.B. (1963) Beams on Elastic Subgrade and the Winkler's Hypothesis. Proceedings of the 5th International Conference of Soil Mechanics, 845-850.

[7] Sall, O.A., Fall, M., Berthoud, Y. and Ba, M. (2013) Influence of the Elastic Modulus of the Soil and Concrete Foundation on the Displacements of a Mat Foundation. Open Journal of Civil Engineering, 3, 228-233. http://dx.doi.org/10.4236/ojce.2013.34027 